\section{Input processing at first exposure to a sign language}

Second Language Research 2015, Vol. 3I (4) 443-463

(C) The Author(s) 2015

Reprints and permissions: sagepub.co.uk/journalsPermissions.nav DOI: I0.I I77/02676583I5576822 slr.sagepub.com

@SAGE

\title{
Gerardo Ortega
}

Radboud University, and Max Planck Institute for Psycholinguistics, Nijmegen The Netherlands

\section{Gary Morgan}

City University London, and University College London, UK

\begin{abstract}
There is growing interest in learners' cognitive capacities to process a second language (L2) at first exposure to the target language. Evidence suggests that $L 2$ learners are capable of processing novel words by exploiting phonological information from their first language (LI). Hearing adult learners of a sign language, however, cannot fall back on their $\mathrm{LI}$ to process novel signs because the modality differences between speech (aural-oral) and sign (visual-manual) do not allow for direct cross-linguistic influence. Sign language learners might use alternative strategies to process input expressed in the manual channel. Learners may rely on iconicity, the direct relationship between a sign and its referent. Evidence up to now has shown that iconicity facilitates learning in non-signers, but it is unclear whether it also facilitates sign production. In order to fill this gap, the present study investigated how iconicity influenced articulation of the phonological components of signs. In Study I, hearing non-signers viewed a set of iconic and arbitrary signs along with their English translations and repeated the signs as accurately as possible immediately after. The results show that participants imitated iconic signs significantly less accurately than arbitrary signs. In Study 2, a second group of hearing non-signers imitated the same set of signs but without the accompanying English translations. The same lower accuracy for iconic signs was observed. We argue that learners rely on iconicity to process manual input because it brings familiarity to the target (sign) language. However, this reliance comes at a cost as it leads to a more superficial processing of the signs' full phonetic form. The present findings add to our understanding of learners' cognitive capacities at first exposure to a signed $L 2$, and raises new theoretical questions in the field of second language acquisition.
\end{abstract}

\section{Keywords}

first exposure, iconicity, L2, sign language

\section{Corresponding author:}

Gerardo Ortega, Center for Language Studies, Radboud University and Max Planck Institute for Psycholinguistics, Wundtlaan I, Kamer 304, Nijmegen, 6525XD, The Netherlands.

Email: gerardo.ortega@mpi.nl 


\section{Introduction}

The topic of input processing at first exposure to a second language (L2) is gaining interest in the field of second language research. It has been suggested that two of the problems that learners face at first contact with the target language are: (1) the segmentation of the word from an unintelligible acoustic stream, and (2) the mapping of form and meaning (Klein, 1986). These issues, however, presuppose that the L 2 is expressed in the acoustic modality (speech) and that the relationship between a linguistic label and its referent is arbitrary in nature. Hearing adults who go on to acquire a sign language as a second language, however, are confronted with a somewhat different scenario. The target language is expressed in the manual modality, and many signs can be easily linked to their meaning because their linguistic form is motivated by the visual characteristics of their referent (i.e. they are iconic). Unlike learners of a spoken L2, sign L2 learners have to determine the boundaries of signs within a continuous string of hand movements (Orfanidou et al., 2010) and must interpret the meaning of a sign that may or may not resemble the concept it represents. Therefore, the strategies to deal with these modalityspecific difficulties might differ significantly to those faced by learners of a spoken L2.

There is good evidence that at the earliest stages of L2 acquisition, learners fall back on their first language (L1) when processing L2 input. Learners often use L1 phonology to segment the target language (e.g. Gullberg et al., 2010), and in production they often substitute L2 sounds with elements from their own phonological repertoire (Carroll, 2013; Flege, 1992). A question that remains widely unexplored is how L2 learners of a sign language cope with the task of discriminating the relevant linguistic elements from a continuous visual signal when the $\mathrm{L} 1$ cannot be recruited as an aid. At the phonological level, for instance, learners' L1 cannot exert any influence on the L2 because the modality differences between speech (aural-oral) and sign (visual-manual) make it impossible for direct cross-linguistic influence to take place. However, hearing adults with no knowledge of a sign language have access to the meaning of iconic signs because their structures are motivated by the form of their referent (Klima and Bellugi, 1979; Taub, 2001). For example, the sign TO-EAT ${ }^{1}$ in many sign languages depicts a person raising food to their mouth. Despite their lack of a signed lexicon, non-signers can associate the form of many iconic signs with their meaning. Sign iconicity has been shown to have a positive effect in remembering new signs (Baus et al., 2012; Campbell et al., 1992; Lieberth and Gamble, 1991), but it has not been investigated how access to the meaning of a sign (via iconicity) is involved in production accuracy. In an attempt to uncover how sign articulation is affected by learners' awareness of the meaning of signs, the current study explores the role of iconicity in the production of the phonological constituents of signs in British Sign Language (BSL).

\section{Input processing at first exposure to an L2}

What learners do at first exposure to an L2 reveals what aspects of the input they regard as relevant. The Input Processing Principles establish that learners tend to process the meaning of a word before they process its form (Van Patten, 1996). However, recent evidence suggests that even true beginners are capable of processing the form of the 
target spoken language by relying on their L1. It has been suggested that processing an L2 through L1 mediation is only possible when both languages share the same features (Schwartz and Sprouse, 1996). This claim has been supported by a series of studies that convincingly show that learners are capable of analysing the form of target structures at the very onset of their L2 learning.

Gullberg et al. (2010) exposed Dutch speakers to naturalistic but controlled weather reports in Mandarin and tested their capacity to identify target words based on minimal exposure to a typologically distant L2. Results showed that learners succeeded in recognising target words, especially disyllabic over monosyllabic words. The authors suggested that participants were making use of cues in their L1 to identify and segment words from the novel language (disyllabic words are common in Dutch). Following a similar paradigm, Han and Liu (2013) exposed Japanese and American participants to video vignettes in Chinese to investigate learners' capacity to process naturalistic L2 input. They found that in general both groups were capable of processing the form of L2 words, in particular when task demands were low. Interestingly, Japanese participants outperformed the American group in a task aimed at discriminating tone, a phonological feature absent in English. Both groups were somewhat capable of processing novel L2 forms but the Japanese group exhibited a significant advantage at identifying prosodic features of the target language due to the typological similarities between their L1 and L2. The strong effects of the L1 were further attested in a separate study investigating the processing of German names by English speakers. Carroll (2013) found that participants were better and faster at learning German names that had an English cognate (e.g. Martina) and that during production learners articulated L2 names with an L1 pronunciation. Learners' dependence on the L1 might be so strong that it may actually hinder the processing of L2 input. Further, Finn and Hudson Kam (2008) found that, when exposed to an artificial language, learners were unable to segment words that presented syllabic clusters that were illegal in their L1. This inability persisted even after prolonged exposure to the target structure.

Taken together, these studies provide evidence that form is available to true beginners at first exposure to an L2 because they exploit phonological information from their L1 to segment and articulate new words. The benefits of relying on the L1 are augmented when L1 and L2 are typologically related or, more precisely, when the target structures are present in both languages (Schwartz and Sprouse, 1996). As stated by Han and Liu (2013), the L1 brings familiarity to the target language.

A novel question in the field of second language research is what happens when learners go on to acquire a second language in a different modality. Sign L2 learners cannot fall back on the phonological information from their L1 because the phonotactic features of spoken words cannot be used as a template for processing a manual language. As such, sign L2 learners are likely to turn to alternative strategies when processing signs for the first time.

\section{Sign language structure and iconicity}

One of the most exciting discoveries of the twentieth century is that sign languages are fully-fledged linguistic systems exhibiting all levels of organization found in spoken 
languages (i.e. a phonology, morphology, syntax) (Sandler and Lillo-Martin, 2006). Signs have a phonological structure whereby a finite number of sub-lexical elements can be combined together to generate meaningful units (Brentari, 1999; Stokoe, 1960; van der Kooij, 2002). The four main components of signs include the configuration of the hand (handshape), the place of articulation (location), the position of the hand with respect to a plane (orientation), and the trajectory the hand follows in space (movement). ${ }^{2}$ Each parameter plays a distinct role during lexical access by deaf and proficient hearing adult signers (Carreiras et al., 2008; Dye and Shih, 2006; Shook and Marian, 2012) and they are gradually mastered by deaf children and hearing adults. Developmental studies have shown that location is the first parameter to be acquired, handshape is the most difficult, and movement falls in between (Conlin et al., 2000; Marentette and Mayberry, 2000; Morgan, 2006). There are few empirical studies investigating the emergence of a visual phonological system in hearing L2 learners but the scant evidence suggests that they are also mastered at different stages, both in production (Jissink, 2005; Ortega, 2013) and perception (Bochner et al., 2011). Despite there not being general consensus of an order of acquisition of the parameters of signs, evidence suggests that each parameter has its own intrinsic complexity, and as a result they are mastered at different stages by L2 learners.

An important feature of sign languages is iconicity: the direct relationship between a linguistic manual form and its referent (Klima and Bellugi, 1979; Taub, 2001; for a review, also see Perniss et al., 2010). Iconicity is instantiated in different ways (Mandel, 1977; Sutton-Spence and Woll, 1999; Taub, 2001). As shown in Figure 1, iconic signs can be a representation of an action (e.g. the BSL sign TO-BRUSH depicts someone brushing his/her hair), they can point at imaginary referents (e.g. the sign TIME points to the position of a watch), or they have similar form to the emblems used by the surrounding speaking community (e.g. the sign HOPE). However, not all signs are iconic. The arbitrary sign SISTER, for instance, cannot be mapped visually to the concept it represents (see Figure 1). Iconicity can also be expressed at the sub-lexical level in that the individual components of signs may have direct mappings to its referent (e.g. a closed fist may represent the roundness of a rock) (Cuxac, 1999; Pietrandrea, 2002).

Regardless of whether the form of a sign evokes visual features of its referent, a crucial characteristic of iconic and arbitrary signs is that both are made up of phonological components. That is, both iconic and arbitrary signs consist of the permissible sub-units available in the phonological repertoire of a given sign language. An intriguing question is whether iconicity, which has proven to be a helpful strategy in some realms of sign L2 learning, also has an effect in the production of the phonological constituents of signs.

\section{Iconicity and sign language learning}

There is growing evidence that iconicity plays a beneficial role in vocabulary learning. Lieberth and Gamble (1991) found that when presented with a list of iconic and arbitrary signs, iconic signs were recalled more accurately by hearing non-signers in short and longer periods after initial exposure. Campbell, Martin, and White (1992) replicated these findings by showing that BSL learners and non-signers alike were more successful at recalling and naming iconic over arbitrary signs despite their different levels of 


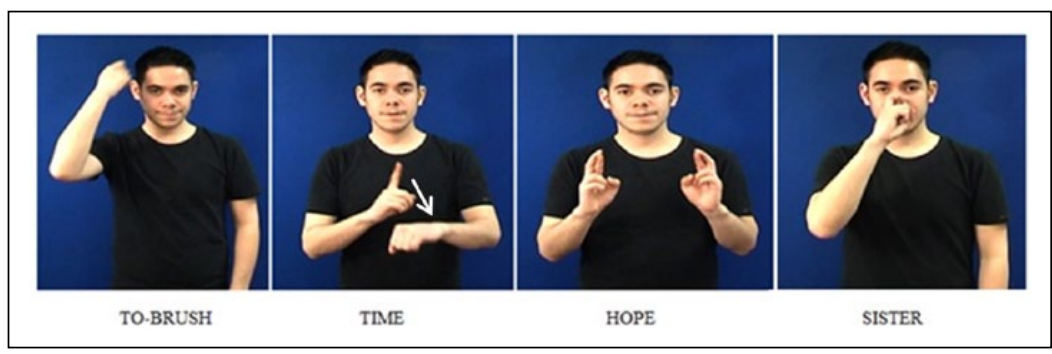

Figure I. Examples of iconic and arbitrary BSL signs. The sign TO-BRUSH is pantomime of brushing, TIME is produced by pointing at an imaginary watch and HOPE is an emblem used in many Western cultures. The form of the sign SISTER does not have clear links with its referent.

proficiency in BSL. More recently, a study investigating the effect of iconicity in sign translation showed that non-signers were faster and more accurate at translating into English iconic than arbitrary signs (Baus et al., 2012). Together, these studies show that iconic signs are more memorable than arbitrary signs by people with no prior experience with a sign language. However, it is unclear how iconicity may affect the processing of the form of a sign by L2 learners or how it may influence sign production.

Regardless of the modality, second language learners have to determine the contrastive components of an L2 word. Phonological discrimination is a critical stage in L2 acquisition because it is the precursor to the development of an L2 phonological system (Escudero and Boersma, 2004). In the case of spoken words, learners have to determine the different sounds that make up a word to gradually develop categories for the new phonological system. In the visual modality, learners also have to decompose signs to determine their phonological constituents (handshape, location, movement and orientation) and to develop a manual phonological inventory. Learners at the earliest stages of sign L2 acquisition thus reveal which of the sign components are more difficult to discriminate and, importantly, show the effect of iconicity on sign articulation before the development of (visual) phonological representations.

\section{The present study}

In order to test the effect of iconicity on sign production, a sign repetition task was administered to a group of non-signing hearing adults. In the spoken modality, the nonword repetition task is a technique used to study language processing mechanisms through the repetition of permissible non-existing words (Coady and Evans, 2008). The task involves transforming the acoustic signal into a recognisable linguistic form (e.g. $w u g)$, breaking it down into its components $(w-u-g)$, re-assembling them into an understandable lexical form (wug), and finally articulating the word. When the process occurs without interference, the input should match the output. The mismatch between input and output is seen as evidence of a disruption in one of the stages of the process. The non-word repetition paradigm has been successfully adapted to the visual modality to 
assess signers' phonological awareness in typical and atypical populations (Mann et al., 2010; Mason et al., 2010). The sign repetition task involves similar stages: participants perceive a sign, decompose it into its components (handshape, location, movement and orientation), assemble the perceived components, and articulate them into a lexical sign.

By administering a sign ${ }^{3}$ repetition task to hearing non-signers it will be possible to assess their ability to process the form of BSL signs at first exposure. In other words, it will be possible to investigate learners' ability to perceive and articulate the components of signs (handshape, location, movement, and orientation). Manipulation of the visual stimulus (iconic vs. arbitrary signs) while controlling for phonological complexity across both sets of signs will help determine the effect of iconicity during sign articulation. The null hypothesis of the study is that both arbitrary and iconic signs will be articulated with the same accuracy because both sets of signs have the same articulatory complexity. The alternative hypothesis is that iconicity will have an effect on sign articulation. Iconicity could boost performance in the articulation of iconic signs in the same way that it aids naming, recall and translation (Baus et al., 2012; Campbell et al., 1992; Lieberth and Gamble, 1991). Alternatively, iconic signs could be articulated less accurately because participants will focus on the meaning of the sign rather than its precise phonological form.

\section{Study I}

\section{Methodology}

$a$ Participants. Fifteen hearing adults ( 7 females, mean age $=23.93$ years) were recruited. All participants spoke English as their native language and did not have prior knowledge of any sign language.

b Stimuli. The video stimuli consisted of individual BSL signs taken from a previous study that collected ratings for iconicity, familiarity and age of acquisition from deaf signers (Vinson et al., 2008). For the purpose of the present study, the same video clips were rated for iconicity by a group of 15 hearing non-signers (five male, mean age: 28.7 years, $S D$ : 9.97 years) on a 7-point Likert scale. The raters were monolingual native speakers of English and had resided in the UK all their lives. None of them reported having any knowledge of BSL, and they did not take part in the actual experiments. Raters were presented with the signs (one at a time) along with their English translation and were asked to rate the degree to which the sign depicted its referent (i.e. its meaning). In the scale 1 denoted low iconicity and 7 indicated high iconicity. After calculating mean iconicity ratings for all signs, a 3.5 cut-off point was established to divide arbitrary from iconic signs. Arbitrary signs were those with ratings lower than 3.5. This threshold has been previously used in other psycholinguistic studies using the same video clips (Thompson et al., 2009). The stimulus materials consisted of 96 sign, of which 48 were iconic (mean iconicity rating: $5.72, S D=.85$ ) and 48 arbitrary (mean iconicity rating: $1.98, S D=.66)$.

The stimuli were selected so that all phonological parameters in both conditions were balanced for phonological complexity: signs were selected so that there were a balanced 
number of movement, handshape, and location types. Because of the limited literature on orientation and its marked features this parameter could not be balanced.

Movement may involve (1) transition of the hands across the space to reach a location on the body or in neutral space (path), (2) repetitive movements within the hands (internal) or (3) both path and internal movements within the sign. The stimuli were selected so that signs in both conditions had an equal number of path, internal or both movement types. With regard to handshape, stimuli were selected so that iconic and arbitrary signs included approximately the same number of marked and unmarked handshapes. Following Sutton-Spence and Woll (1999), the unmarked handshapes were 3 (open hand with extended and adducted fingers), f) (pointing index), and (closed fist). In addition, because some signs have a transition from one handshape to another, the stimuli were also selected so that both conditions had a balanced number of signs with these changes. Finally, the place of articulations for all signs was also balanced so that signs in both conditions were articulated in the same set of locations. Appendices 1-3 show a full description of the sign stimuli, their phonological structure and their iconicity ratings.

c Procedure. Participants were tested individually in a quiet room on a laptop PC with a 15 -inch $(38 \mathrm{~mm})$ screen. A video camera was located $1.5 \mathrm{~m}$ from participants at a 45 degree angle to record all sign repetitions. The task consisted of three phases. At the beginning of each trial, a fixation point appeared in the middle of the screen for 1,000 ms. During the priming phase, a lower case English word in black letters was displayed for $2,000 \mathrm{~ms}$. In the perception phase, a video clip of the BSL sign was presented. After the video clip stopped and disappeared from the screen participants started the production phase in which they had 5,000 ms to replicate the sign as accurately as possible. Participants were explicitly instructed to imitate the sign as accurately as possible after the sign had disappeared from the screen. This forced them to produce the sign from memory and not self-correct their articulations during the perception phase. Trials of iconic and arbitrary signs were presented in randomised order. Participants completed a practice trial with ten word-sign pairs different from the experimental items before taking part in the actual experiment. These consisted of both iconic and arbitrary signs and none of them were included in the actual experiment.

d Coding and reliability. After the data were collected, the videos of each participant's articulations were entered into the linguistic annotator programme ELAN (Lausberg and Sloetjes, 2009), and each BSL sign was glossed with its English translation. Articulation accuracy for all signs was measured independently for each formational parameter by two researchers adhering to the following coding scheme.

- Handshape: most signed phonological models consider this parameter to be defined by a set of selected fingers with a specific configuration (Brentari, 1999; van der Kooij, 2002). If participants' handshapes did not use the correct selected fingers or had an inaccurate configuration, these renditions were coded as incorrect.

- Movement: if participants failed to produce the exact form of the movements (i.e. path, internal or both), they were regarded as errors. In addition, common errors 
in sign L2 learners are not using the target joint (Rosen, 2004). Learners often produce errors typically referred to as proximalizations when they move nontarget joints that are closer to the torso (e.g. shoulders instead of elbows) or distalization errors when they move non-target joints away from the torso (e.g. knuckles instead of wrists). Sign production was regarded as accurate if participants moved the same joints as in the model (i.e. no proximalized or distalized movements were permitted).

- Location: this parameter could be articulated in neutral signing space in front of the torso or on a specific body part. Signs in neutral signing space were always articulated right in front of the model, so inaccurate locations were those articulated in the ipsilateral or contraipsilateral sides of participants. For signs articulated on a part of the body, participants' hands had to reach the same location as the model with a $\pm 20 \mathrm{~mm}$ tolerance. Signs articulated away from the torso were not regarded as incorrect locations because they were the result of recruiting proximal instead of distal joints (these were regarded as movement errors). This rationale is based on studies showing that phonetic variation of location is the result of the increase or decrease of sign movement (Crasborn, 2001).

- Orientation: there is limited information about this parameter so it was decided that an orientation error would be that deviating 45 degrees or more from the model's production. The margin of error for location and orientation were the most stringent measure that could be achieved from the video recordings.

Participants were instructed to imitate the signs as accurately as possible. If the phonological parameters fell within the pre-established coding criteria, the sign was assigned a score of 1; if it was different, the sign was assigned a score of zero. It is the case that signs' citation forms are altered during naturalistic signing and undergo phonetic processes such as preservation, anticipation, hold reduction, and movement deletions (Liddell and Johnson, 1989; Sandler, 1989). However, signs were presented in isolation so that they were not prone to such articulatory variation. In addition, the task aimed to establish non-signers' abilities to discriminate and articulate the phonological components of signs so that even if participants' renditions presented permissible variations they were still regarded as errors. Two researchers coded independently all participants' articulations and reached $85 \%$ agreement. Disagreements were discussed and resolved until $100 \%$ agreement was reached.

\section{Results}

We calculated the proportion of correct renditions for each phonological parameter in both conditions and conducted a sign type (iconic, arbitrary) $\times$ phonological parameter (handshape, location, movement and orientation) repeated measures $2 \times 4$ ANOVA across participants $\left(F_{1}\right)$ and items $\left(F_{2}\right)$. The analysis per participant $\left(F_{1}(1,14)=5.91\right.$, $\left.p=.03, \eta^{2}=.30\right)$ but not per item $\left(F_{2}(1,47)=3.35, p=.07, \eta^{2}=.07\right)$ revealed that there was a main effect of iconicity. Articulation accuracy for iconic signs was significantly lower $(M=.77, S D=.11)$ than for arbitrary signs $(M=.80, S D=.10)$. The analysis also revealed that there was a strong main effect of parameter $\left(F_{l}(3,42)=77.60, p<.001\right.$, 
Table I. Proportion of articulation accuracies per phonological parameter and sign type (sign presented with English translation).

\begin{tabular}{lll}
\hline Phonological parameter & \multicolumn{2}{l}{ Sign type } \\
\cline { 2 - 3 } & Iconic & Arbitrary \\
\hline Handshape & $0.54(0.07)$ & $0.60(0.20)$ \\
Location & $0.91(0.11)$ & $0.93(0.09)$ \\
Movement & $0.73(0.11)$ & $0.79(0.18)$ \\
Orientation & $0.89(0.13)$ & $0.89(0.12)$ \\
\hline
\end{tabular}

Note. Maximum score $=1.00$ The value in brackets represents standard deviations.

$\left.\eta^{2}=.85 ; F_{2}(3,141)=83.46, p<.001, \eta^{2}=.64\right)$. Pairwise $t$-tests after Bonferroni corrections revealed that accuracy of articulation for handshape $(M=.57, S D=.14)$, location, $(M=.92, S D=.05)$, movement $(M=.76, S D=.13)$, and orientation $(M=.88, S D=.05)$ was significantly different from each other. Namely, handshape was different from location $(t(14)=11.14, p<.001)$, movement $(t(14)=2.81, p=.01)$, and orientation $(t(14)=$ $9.59, p<.001)$. Location was found to be significantly different from orientation $(t(14)$ $=4.51, p<.001)$, and movement $(t(14)=10.57, p<.001)$. In the same way, movement and orientation were significantly different from one another $(t(14)=7.42, p<.001)$. There was no significant interaction between iconicity and phonological parameter $\left(F_{1}(3,42)=2.07, p=.12, \eta^{2}=.13 ; F_{2}(3,141)=.67, p=.57, \eta^{2}=.01\right)$.

Table 1 shows that there is a clear tendency for iconic signs to exhibit a lower accuracy in their formational parameters than arbitrary signs. To further corroborate whether iconicity hindered sign articulation, iconicity ratings were rank ordered and correlated with degree of accuracy. A Pearson product-moment correlation coefficient revealed that there was a statistically significant negative correlation between these two measures $(r=$ $-.19, n=96, p=.03$ ), suggesting that as iconicity ratings increase, articulation accuracy decreased accordingly.

The analysis of the present sign repetition task shows that accuracy of articulation of each phonological parameter is significantly different from each other, with handshape being the least accurately produced, followed by movement, then orientation and finally location. The analysis also revealed that participants were significantly more accurate at producing arbitrary over iconic signs in the sign unit and in each phonological parameter.

It could be argued, however, that the presence of the English word acted as a prime and was the source of a higher proportion of articulation errors in iconic signs. The English prime may have activated a visual representation and distracted participants from processing the exact phonological parameters of iconic signs. It is also possible that the prime acted as a cue to recognise the iconic features of a sign thus interfering in the perception and articulation of the sign parameters. In either case, the errors produced would be driven by the English word and not by the iconic features of the signs. In order to test whether the English prime was the cause behind a higher proportion of errors in iconic signs, a different group of participants took part in another sign repetition task which did not include a word cue (i.e. without word prime). 


\section{Study 2}

\section{Methodology}

a Participants. Participants for this study were 15 hearing non-signers ( 6 female, mean age $=23.66$ years), none of whom took part in Study 1 . All were native speakers of English and none reported having knowledge of BSL or any other sign language.

b Procedure. The same signed stimuli from Study 1 were used but there was no English translation before the sign video was displayed. Participants followed the same instructions as in Study 1, that is, they were told to imitate the signs shown as accurately as possible only after the video had stopped and disappeared from the screen. At the beginning of each trial, a fixation point appeared in the middle of the screen for 1,000 ms. Then, the BSL sign was shown for all of its duration. Only when the video clip had stopped and disappeared from the screen were participants given up to 5,000 $\mathrm{ms}$ to imitate the sign as accurately as possible. The same stimulus materials from Study 1 were used in this study and all 96 signs (48 iconic and 48 arbitrary) were presented in randomised order. Participants completed a practice trial with 10 signs before taking part in the actual experiment, and these were not included as experimental items. As in Study 1, after the data were collected, two independent researchers coded for articulation accuracy for each phonological parameter. There was $90 \%$ intercoder agreement, and after discussion a $100 \%$ agreement was reached.

\section{Results}

Following the same procedure as in Study 1, we calculated the proportion of correct renditions for each phonological parameter in both conditions. A sign type (iconic, arbitrary) $\times$ phonological parameter (handshape, location, movement and orientation) repeated measures $2 \times 4$ ANOVA across participants $\left(F_{1}\right)$ and items $\left(F_{2}\right)$ revealed that there was a main effect of iconicity $\left(F_{1}(1,14)=13.68, p=.002, \eta^{2}=0.49 ; F_{2}(1,47)=\right.$ $\left.4.06, p=.05, \eta^{2}=.08\right)$. Participants produced iconic signs significantly less accurately $(M=.77, S D=.01)$ than arbitrary signs $(M=.81, S D=.01)$. There was also a main effect on phonological parameter $\left(F_{1}(1,14)=112.93, p<.001, \eta^{2}=.89 ; F_{2}(3,141)=50.11\right.$, $\left.p<.001, \eta^{2}=.52\right)$. Pairwise $t$-tests after Bonferroni corrections showed that articulation accuracy for handshape $(M=.62, S D=.02)$, location, $(M=.94, S D=.01)$, movement $(M=.73, S D=.02)$, and orientation $(M=.90, S D=.01)$ were significantly different from each other. Handshape was articulated significantly differently from location $(t(14)=$ 9.26, $p<.001)$, movement $(t(14)=3.81, p<.001)$, and orientation $(t(14)=9.68, p<$ $.001)$. Location was articulated significantly differently from movement $(t(14)=11.02$, $p<.001)$ and orientation $(t(14)=4.36, p<.001)$. Movement was articulated significantly differently from orientation $(t(14)=7.29, p<.001)$. The interaction between iconicity and parameter was not significant $\left(F_{1}(1,14)=1.67, p=.19, \eta^{2}=.11 ; F_{2}(1,47)=.62\right.$, $\left.p=.60, \eta^{2}=.01\right)$.

Table 2 shows that there was a tendency for the phonological parameters in iconic signs to be less accurately produced than arbitrary signs. Iconicity ratings were rank 
Table 2. Proportion of articulation accuracies per phonological parameter and sign type (sign presented without English translation).

\begin{tabular}{lll}
\hline Phonological parameter & \multicolumn{2}{l}{ Sign type } \\
\cline { 2 - 3 } & Iconic & Arbitrary \\
\hline Handshape & $0.61(0.11)$ & $0.64(0.09)$ \\
Location & $0.94(0.04)$ & $0.94(0.04)$ \\
Movement & $0.70(0.10)$ & $0.76(0.11)$ \\
Orientation & $0.87(0.07)$ & $0.91(0.05)$ \\
\hline
\end{tabular}

Note. Maximum score $=1.00$ The value in brackets represents standard deviations.

ordered and correlated with articulation accuracy. A Pearson product-moment correlation coefficient revealed that as iconicity increased, the articulation accuracy decreased accordingly $(r=-.14, \mathrm{n}=96, p=.03)$.

These results replicate the findings reported in Study 1. All the phonological parameters were articulated significantly different from each other, with location being the most accurate, followed by orientation, movement and finally handshape. Importantly, the data show that iconic signs were articulated less accurately than arbitrary signs even in the absence of a word prime. In addition, the negative effect of iconicity can also be observed at the sub-lexical level because all the phonological components of signs were articulated less accurately in iconic signs.

\section{Discussion}

Studies on first exposure to an L2 propose that true beginners are capable of processing the form of target words by relying on the phonological properties of their L1 (Finn and Hudson Kam, 2008; Gullberg et al., 2010; Han and Liu, 2013). This position is contrary to some views claiming that before processing words for form, they are first processed for meaning (Van Patten, 1996). The question addressed in the current study was what happens when learners are first exposed to a sign language as L2, where the L1 cannot be recruited as a learning aid due to modality differences (speech vs. sign). Iconicity, a feature that allows access to the meaning of signs, has been shown to aid learning (Baus et al., 2012; Campbell et al., 1992; Lieberth and Gamble, 1991). It was therefore assumed that iconicity could also be used as a strategy to process novel linguistic input in the manual modality. The two studies presented here used sign repetition tasks to investigate how iconicity influenced the production of BSL signs by hearing non-signers. The results showed that articulation of iconic signs was less accurate than for arbitrary signs at the lexical and sub-lexical level and that it varied inversely as a function of degree of iconicity (i.e. lower articulation accuracy as iconicity ratings increased). The same results were found in Study 2 when the sign translation was not made available to participants, which suggests that the English prime was not the source of the articulation errors. Lower accuracy was not the consequence of iconic signs being at an articulatory disadvantage, as stimuli in both conditions were balanced for phonological complexity. 


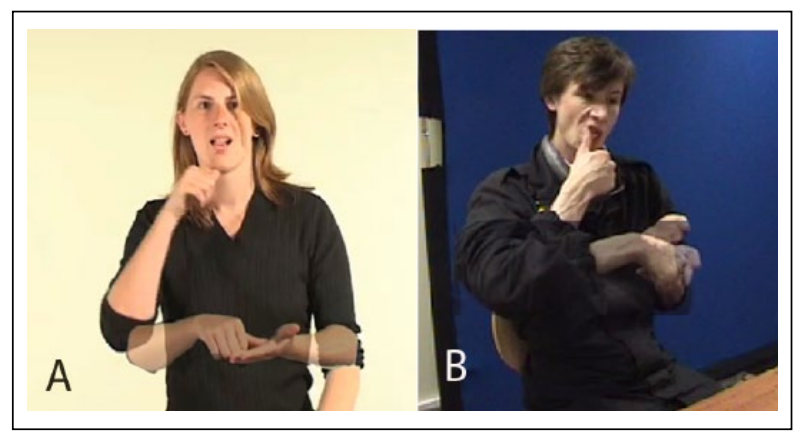

Figure 2. Example of a participant's imitation of a sign where the iconic element was preserved but not its exact constitution. The location of the sign LETTER is the chin (2a) but the participant substituted it for the tongue, which is more iconically motivated $(2 b)$. Source. Figure 2a adapted from the stimulus materials (Vinson et al., 2008).

Two explanations for these findings are considered. First, it is possible that when access to the meaning of signs is readily accessible to non-signers via iconicity fewer resources are channelled towards the processing of the signs' exact linguistic forms. During the experiment, participants might have centred their attention on the mental image generated by an iconic sign and linked this to the sign meaning. Having accessed these iconic features, participants then executed a manual form that retained the iconic elements of the stimulus but did not incorporate the exact phonological components of the actual sign. The sign LETTER, for instance, represents a person putting a stamp on an envelope and has as initial location the signer's chin (Figure 2a). As can be observed in Figure 2b, one participant was aware of the iconic motivation of the sign because he re-enacted the action of licking a stamp. However, the execution of the sign was somewhat inaccurate because he replaced the actual location (i.e. the chin) for another that was iconically motivated (i.e. the tongue). The mechanism of input processing was different for arbitrary signs. Non-iconic structures did not evoke a mental image that could be mapped as easily to a referent (e.g. the sign SISTER does not have physical resemblance with its referent). As such, arbitrary signs were manual forms void of meaning that needed to be imitated accurately. When processing signs that were less easily matched to a referent, participants had to focus their attention on their exact form in order to imitate them with precision.

This interpretation is compatible with previous research showing that despite its positive effect in sign recall (Baus et al., 2012; Campbell et al., 1992; Lieberth and Gamble, 1991), iconicity has a negative effect in form-based tasks. In a phonological decision task, BSL users were asked to determine as fast and accurately as possible whether a list of iconic and arbitrary signs had straight or curved hand configurations (Thompson et al., 2010). It was found that judgments for iconic signs were significantly slower and less accurate than for arbitrary signs. The authors argued that the processing of iconic signs is less dependent on phonological mediation and that automatic access to the signs' meaning interferes in the capacity to make form-based judgments. A similar effect seems to be observed in the hearing non-signers in the current study. Iconicity allowed easy 
access to the meaning of signs, thus making the processing of the exact form of the sign less relevant. These results would somewhat support the Input Processing Principles (Van Patten, 1996) in that sign L2 learners' default strategy is to process novel input for meaning before form. However, it is important to note that this learners' strategy is not the same for all signs but rather is driven by the nature of the linguistic input (i.e. whether signs are iconic or arbitrary). When the meaning of a sign is inaccessible due to its arbitrary relationship with a referent, novice signers will focus more on the formal aspects of the target structure, thus yielding higher articulation accuracy.

A second possibility is that speakers' existing ability to generate co-speech gestures interfered in the processing of the phonological constituents of iconic signs. Gestures have a variety of forms and functions with one being that they may reproduce an image of the entity being talked about (iconic gestures) (Kendon, 1995; McNeill, 1992). Communication is enhanced when iconic gestures co-occur with speech (Kelly et al., 2010), which suggests that speakers are sensitive to their iconic properties and exploit them to make sense of a multi-modal utterance (Özyürek et al., 2007).

Many signs are similar in form and meaning with the gestures used in the surrounding speaking community (e.g. the BSL sign TO-DRINK, HOPE and GOOD have a similar structure to the action of drinking and the gestures 'fingers crossed' (1) ). Gestures, however, are a manual form of communication with significant differences to the sign languages used by a deaf community. While signs consist of phonological constituents (handshape, location, movement, and orientation), gestures are holistic units without a systematic sub-lexical organization (McNeill, 1992). Given that the processing of iconic gestures does not require attention to a specific manual phonology, it is possible that participants may have recognised some iconic signs because of their similarities with co-speech gestures and produced their own gesture instead of the signed stimulus. For instance, when asked to imitate the sign TO-WRITE, most participants executed what looked like their own gesture for writing, which deviated from the target handshape . If indeed sign L2 learners process iconic signs as gestures, the lower articulation accuracy compared to arbitrary signs may be attributed to gestural interference.

This interpretation is compatible with previous research showing that when asked to imitate iconic signs, non-signers tend to produce their own gesture en lieu of a conventionalised sign (Ortega and Morgan, 2010; Chen Pichler, 2011). For instance, Chen Pichler (2009) has argued that rather than processing signs' sub-lexical elements, nonsigners recognise gestural elements and produce their own gestures instead of the exact signs' structure. She argues that participants repeatedly misarticulate the handshape of certain target signs (e.g. an extended index finger with opposed thumb for the sign WHERE) because the handshape of their gestures does not share the same form (e.g. the gesture 'wait a minute' is articulated with an unopposed thumb). It must be acknowledged, however, that similarities between a gesture and a sign may not always result in lower articulation accuracy, but in fact may have a positive effect. Previous studies have shown that articulation of iconic signs by hearing non-signers tends to be accurate when the target sign and participants' gesture share the same handshape (Ortega and Özyürek, 2013). This line of argumentation would suggest that learners look for familiarity in the 
input but, rather than resorting to their L1, they fall back on their gestural system which also includes manual iconicity, albeit without phonological constituents.

The results of the present studies would suggest that at first exposure to a signed L2 there is not necessarily a fixed approach for input processing (i.e. meaning first, then form). Rather, it seems that learners adopt a more nuanced strategy and this is modulated by the nature of the linguistic input. When target signs have clear mappings with their referent (i.e. when they are iconic) the processing of form will be more superficial because it is less critical to access meaning. Conversely, when easy access to the meaning is not possible, non-signers will shift more resources to the processing of the linguistic form of a target structure in order to be able to repeat the sign accurately.

Beyond sign languages an interesting empirical question is whether L2 learners of a language with words that mimic the acoustic properties of their referent (i.e. soundsymbolic words) also exhibit poorer performance in the processing of these forms compared with non-sound symbolic words. Japanese, for example, consists of a large number of mimetic verbs (also called gitaigo) whose acoustic properties evoke mental images of motion events (Oda, 2000). Research has shown that children and adult learners of Japanese are sensitive to the iconic elements of mimetic verbs and that the direct links between word and referent facilitate vocabulary learning (Imai et al., 2008; Kantartzis et al., 2011; Reinisch et al., 2013; for a review, see also Imai and Kita, 2014). However, it has not yet been explored whether sound-symbolism facilitates form processing for L2 learners. One possibility is that despite mimetic verbs being more memorable, their exact form will be produced less accurately by L2 learners because the more direct access to their meaning will put less pressure in focusing on the words' exact form.

In sum, our findings show that the iconic links between a sign and its referent make it possible for non-signers to associate novel signs with their meaning at first exposure to a sign language. Despite these links being helpful for learning and recalling iconic signs (Baus et al., 2012; Campbell et al., 1992; Lieberth and Gamble, 1991) they appear to be detrimental for accurate sign production. Future research should determine whether this effect is driven by automatic access to the meaning of iconic signs or is due to gestural interference. What these two possibilities share in common, however, is that iconicity provides access to the meaning of a sign and, as a result, non-signers process linguistic forms at first exposure paying less attention to their exact constituents. It must be acknowledged that iconic mappings may not be the sole factor that governs form processing in sign L2 learners. Non-linguistic factors such as age, form of instruction and individual motivation have been shown to play a key role in L2 phonological acquisition in the spoken modality (Moyer, 1999). Thus it would be reasonable to expect that these factors are also critical in sign L2 acquisition. In addition, given that the present data shows that non-signers were relatively accurate in the articulation of both types of signs, future research should contemplate using a measure of sign phonological complexity to evaluate how it may interact with iconicity during sign articulation. The results from the present study can thus form a baseline from which further research on sign L2 acquisition could elaborate.

Understanding the cognitive resources that learners draw upon at first exposure to a sign language has important theoretical implications in the field of second language research. The fundamental differences between speech and sign open up new questions to the field of L2 research for how learners cope with novel input in a different modality 
from their L1 and what knowledge they draw on to develop new lexical (manual) representations. The present study illuminates the processes involved in the learning of signed languages as L2 as well as contributes to general debates in the wider field, for example, the role of L1 on L2 acquisition. Looking at sign L2 acquisition we can learn more about how learners acquire a visual language and more generally we can delineate those aspects of L2 learning that are modality-specific from those that are common across all language learners.

\section{Acknowledgements}

We would like to thank Alex Lau Zhu and Taffany Leung who assisted in the data collection and Danny McMannus for his help producing the images in Figure 1.

\section{Declaration of conflicting interest}

The authors declare that there is no conflict of interest.

\section{Funding}

This research was supported by the Mexican National Council of Science and Technology (CONACYT, grant 304770), and the Economic and Social Research Council of Great Britain (grant 620-28-600 The ESRC Deafness, Cognition and Language Research Centre).

\section{Notes}

1. By convention sign glosses are written in block capitals.

2. Non-manual features like mouthings, mouth gestures and facial expressions are also phonological constituents of signs (Crasborn et al., 2008; Lewin and Schembri, 2011) but these will not be discussed in the present study.

3. The signs used in the experiment were real BSL signs but because participants had no experience in any sign language the stimuli were perceived as meaningless signs (non-signs).

\section{References}

Baus C, Carreiras M, and Emmorey K (2012) When does iconicity in sign language matter? Language and Cognitive Processes 28: 261-71.

Bochner JH, Christie K, Hauser PC, and Searls JM (2011) When is a difference really different? Learners' discrimination of linguistic contrasts in American Sign Language. Language Learning 61: 1302-27.

Brentari D (1999) A prosodic model of sign language phonology. Cambridge: MIT Press.

Campbell R, Martin P, and White T (1992) Forced choice recognition of sign in novice learners of British Sign Language. Applied Psycholinguistics 13: 185-201.

Carreiras M, Gutiérrez-Sigut E, Baquero S, and Corina D (2008) Lexical processing in Spanish Sign Language (LSE). Journal of Memory and Language 58: 100-22.

Carroll SE (2013) Introduction to the special issue: Aspects of word learning on first exposure to a second language. Second Language Research 29: 131-44.

Chen Pichler D (2009) Sign production by first-time hearing signers: A closer look at handshape accuracy. Cadernos Saude [Special Volume on Sign Languages] 2: 37-50.

Coady JA and Evans JL (2008) Uses and interpretations of non-word repetition tasks in children with and without specific language impairments (SLI). International Journal of Language and Communication Disorders / Royal College of Speech and Language Therapists 43: 1-40. 
Conlin KE, Mirus GR, Mauk C, and Meier RP (2000) The acquisition of first signs: Place, handshape, and movement. In: Chamberlain C, Morford JP, and Mayberry RI (eds) Language Acquisition by Eye. Mahwah, NJ: Lawrence Erlbaum, 51-70.

Crasborn O (2001) Phonetic implementation of phonological categories in Sign Language of the Netherlands. Utrecht: LOT.

Crasborn O, van der Kooij E, Waters D, Woll B, and Mesch J (2008) Frequency distribution and spreading behavior of different types of mouth actions in three sign languages. Sign Language and Linguistics 1: 45-67.

Cuxac C (1999) French Sign Language: proposition of a structural explanation by iconicity. Gesture-Based Communication in Human-Computer 1739: 165-84.

Dye M and Shih S (2006) Phonological priming in British Sign Language. In: Goldstein L, Whalen DH, and Best CT (ed.) Laboratory phonology 8. Berlin: Mouton de Gruyter, 243-63.

Escudero P and Boersma P (2004) Bridging the gap between L2 speech perception research and phonological theory. Studies in Second Language Acquisition 26: 551-85.

Finn A and Hudson Kam C (2008) The curse of knowledge: First language knowledge impairs adult learners' use of novel statitistics for word segmentation. Cognition 108: 477-99.

Flege J (1992) The intelligibility of English vowels spoken by British and Dutch talkers. In: Kent RD (ed.) Intelligibility in speech disorders: Theory, measurement, and management. Amsterdam: John Benjamins, 157-232.

Gullberg M, Roberts L, Dimroth C, Veroude K, and Indefrey P (2010) Adult learning after minimal exposure to an unknown natural language. Language Learning 60: 5-24.

Han $Z$ and Liu Z (2013) Input processing of Chinese by ab initio learners. Second Language Research 29: 145-64.

Imai $\mathrm{M}$ and Kita S (2014) The sound symbolism bootstrapping hypothesis for language acquisition and language evolution. Philosophical Transactions of the Royal Society of London. Series B, Biological Sciences, 369(20130298). doi:dx.doi.org/10.1098/rstb.2013.0298

Imai M, Kita S, Nagumo M, and Okada H (2008) Sound symbolism facilitates early verb learning. Cognition 109: 54-65.

Jissink T (2005) How do you drive a car? Phonological acquisition order for hearing adult learners of Sign Language of the Netherlands. Amsterdam: University of Amsterdam.

Kantartzis K, Imai M, and Kita S (2011) Japanese sound-symbolism facilitates word learning in English-speaking children. Cognitive Science 35: 575-86.

Kelly SD, Özyürek A, and Maris E (2010) Two sides of the same coin: Speech and gesture mutually interact to enhance comprehension. Psychological Science 21, 260-67.

Kendon A (1995) Gestures as illocutionary and discourse structure markers in Southern Italian conversation. Journal of Pragmatics 23: 247-79.

Klein W (1986) Second language acquisition. Cambridge: Cambridge University Press.

Klima E and Bellugi U (1979) The signs of language. Harvard: Harvard University Press.

Lausberg H and Sloetjes H (2009) Coding gestural behavior with the NEUROGES-ELAN system. Behavior Research Methods 41: 841-49.

Lewin D and Schembri AC (2011) Mouth gestures in British Sign Language: A case study of tongue protrusion in BSL narratives. Sign Language and Linguistics 14: 94-114.

Liddell SK and Johnson RE (1989) American Sign Language: The phonological base. Sign Language Studies 64: 195-278.

Lieberth AK and Gamble ME (1991) The role of iconicity in sign language learning by hearing adults. Journal of Communication Disorders 24: 89-99.

Mandel MA (1977) Iconic devices in American Sign Language. In: Friedman A (ed.) On the other hand: New pespectives on American Sign Language. New York: Academic Press, 57-107.

Mann W, Marshall CR, Mason K, and Morgan G (2010) The acquisition of sign language: The impact of phonetic complexity on phonology. Language Learning and Development 6: 60-86. 
Marentette PF and Mayberry RI (2000) Principles for an emerging phonological system: A case study of early ASL acquisition. In: Chamberlain C, Morford JP, and Mayberry RI (eds) Language acquisition by eye. Mahwah, NJ: Lawrence Erlbaum, 71-90.

Mason K, Rowley K, Marshall CR, et al. (2010) Identifying specific language impairment in deaf children acquiring British Sign Language: Implications for theory and practice. British Journal of Developmental Psychology 28: 33-49.

McNeill D (1992) Hand and mind: What gestures reveal about thought. Chicago, IL: University of Chicago Press.

Morgan G (2006) 'Children are just lingual': The development of phonology in British Sign Language (BSL). Lingua 116: 1507-23.

Moyer A (1999) Ultimate attainment in L2 phonology: The critical factors of age, motivation, and instruction. Studies in Second Language Acquisition 21: 81-108.

Oda H (2000) An embodied semantic mechanism for mimetic words in Japanese. Unpublished Doctoral Dissertation, Indiana University, Bloomington, IN, USA.

Orfanidou E, Adam R, Morgan G, and McQueen JM (2010) Recognition of signed and spoken language: Different sensory inputs, the same segmentation procedure. Journal of Memory and Language 62: 272-83.

Ortega G (2013) Acquisition of a signed phonological system by hearing adults: The role of sign structure and iconicity. Unpublished Doctoral Dissertation, University College London, UK.

Ortega G and Morgan G (2010) Comparing child and adult development of a visual phonological system. Language, Interaction, and Acquisition 1: 67-81.

Ortega G and Özyürek A (2013) Gesture-sign interface in hearing non-signers'first exposure to sign. In: Tilburg Gesture Meeting conference proceedings. Tilbrug: Tilburg University, 1-5.

Özyürek A, Willems RM, Kita S, and Hagoort P (2007) On-line integration of semantic information from speech and gesture: insights from event-related brain potentials. Journal of Cognitive Neuroscience 19: 605-16.

Perniss P, Thompson RL, and Vigliocco G (2010) Iconicity as a general property of language: evidence from spoken and signed languages. Frontiers in Psychology 1: 1664-78.

Pichler DC (2011) Sources of handshape error in first-time signers of ASL. In: Mathur G and Napoli DJ (eds) Deaf around the world: The impact of language. Oxford: Oxford University Press, 96-126.

Pietrandrea P (2002) Iconicity and arbitrariness in Italian Sign Language. Sign Language Studies 2: $296-321$.

Reinisch E, Jesse A, and Nygaard LC (2013) Tone of voice guides word learning in informative referential contexts. Quarterly Journal of Experimental Psychology 66: 1227-40.

Rosen RS (2004) Beginning L2 production errors in ASL lexical phonology: A cognitive phonology model. Sign Language and Linguistics 7: 31-61.

Sandler W (1989) Phonological representation of the sign: Linearity and nonlinearity in American Sign Language. Dordrecht: Foris Publications.

Sandler W and Lillo-Martin D (2006) Sign language and linguistic universals. Cambridge: Cambridge University Press.

Schwartz BD and Sprouse RA (1996) L2 cognitive states and the Full Transfer/Full Access model. Second Language Research 12: 40-72.

Shook A and Marian V (2012) Bimodal bilinguals co-activate both languages during spoken comprehension. Cognition 124: 314-24.

Stokoe W (1960) Sign language structure: An outline of the visual communication systems of the American Deaf. Occasional Papers 8. Buffalo, NY: University of Buffalo.

Sutton-Spence R and Woll B (1999) The linguistics of British Sign Language: An introduction. Cambridge: Cambridge University Press.

Taub S (2001) Language from the body: Iconicity and metaphor in American Sign Language. Cambridge: Cambridge University Press. 
Thompson RL, Vinson DP, and Vigliocco G (2009) The link between form and meaning in American Sign Language: Lexical processing effects. Journal of Experimental Psychology. Learning, Memory, and Cognition 35: 550-7.

Thompson RL, Vinson DP, and Vigliocco G (2010) The link between form and meaning in British Sign Language: effects of iconicity for phonological decisions. Journal of Experimental Psychology. Learning, Memory, and Cognition 36: 1017-27.

van der Kooij E (2002) Phonological categories in Sign Language of the Netherlands: The role of phonetic implementation and iconicity. Utrecht: LOT.

Van Patten B (1996) Input processing and grammar instruction in second language acquisition. Norwood, NJ: Ablex.

Vinson DP, Cormier K, Denmark T, Schembri A, and Vigliocco G (2008) The British Sign Language (BSL) norms for age of acquisition, familiarity, and iconicity. Behavior Research Methods 40: 1079-87.

Appendix I. Phonological information of the signed stimuli in the arbitrary and iconic conditions.

\begin{tabular}{|c|c|c|}
\hline \multirow[t]{2}{*}{ Parameter } & \multicolumn{2}{|l|}{ Condition } \\
\hline & Arbitrary & Iconic \\
\hline \multicolumn{3}{|l|}{ Movement: } \\
\hline Path & 27 & 25 \\
\hline Local & 14 & 14 \\
\hline Both & 7 & 9 \\
\hline Total & 48 & 48 \\
\hline \multicolumn{3}{|l|}{ Handshape: } \\
\hline Marked & 21 & 24 \\
\hline Unmarked & 22 & 19 \\
\hline Change & 5 & 5 \\
\hline Total & 48 & 48 \\
\hline \multicolumn{3}{|l|}{ Location: } \\
\hline Arms & I & I \\
\hline Cheek & I & I \\
\hline Chest & - & I \\
\hline Ear & I & I \\
\hline Elbow & I & - \\
\hline Eyes & I & 2 \\
\hline Finger & 8 & 6 \\
\hline Hand & 5 & 3 \\
\hline Head & 3 & 4 \\
\hline Mouth & I & 3 \\
\hline Neck & I & I \\
\hline Nose & I & I \\
\hline Palm & 8 & 5 \\
\hline Waist & - & I \\
\hline Wrist & - & I \\
\hline Signing & 16 & 17 \\
\hline \multicolumn{3}{|l|}{ space } \\
\hline Total & 48 & 48 \\
\hline
\end{tabular}


Appendix 2. List of arbitrary signs and their phonological properties.

\begin{tabular}{|c|c|c|c|c|c|c|}
\hline & Gloss & Iconicity & Sign type & Movement & Location & Handshape \\
\hline 1 & WHAT & 1.53 & Type I & Local & Signing space & unmarked \\
\hline 2 & FROM & 2.40 & Type I & Local & Signing space & unmarked \\
\hline 3 & SATURDAY & 1.07 & Type I & Local & Signing space & unmarked \\
\hline 4 & EUROPE & 1.33 & Type I & Path & Signing space & marked \\
\hline 5 & SCHOOL & 1.33 & Type I & Path & Signing space & marked \\
\hline 6 & NORWAY & 1.93 & Type I & Path & Signing space & marked \\
\hline 7 & MORE & 2.47 & Type I & Path & Signing space & marked \\
\hline 8 & WALES & 1.93 & Type I & Both & Signing space & Change (bend) \\
\hline 9 & BULGARIA & 1.33 & Type 2 & Both & Mouth & Change (close) \\
\hline 10 & REFUSE & 2.13 & Type 2 & Both & cheek & Change (open) \\
\hline II & BED & 2.27 & Type 2 & Path & Head & marked \\
\hline 12 & YELLOW & 1.27 & Type 2 & Local & ear & marked \\
\hline 13 & CRUEL & 2.60 & Type 2 & Local & Side neck & unmarked \\
\hline 14 & BROWN & 1.20 & Type 2 & Path & Elbow & unmarked \\
\hline 15 & RUDE & 2.73 & Type 2 & Path & Arm & marked \\
\hline 16 & SISTER & 1.00 & Type 2 & Path & Nose & marked \\
\hline 17 & FIRE & 2.60 & Type 3 & Both & Signing space & unmarked \\
\hline 18 & MAGIC & 2.67 & Type 3 & Both & Signing space & Change (open) \\
\hline 19 & TEACH & 1.53 & Type 3 & Path & Signing space & marked \\
\hline 20 & DOG & 2.33 & Type 3 & Path & Signing space & marked \\
\hline 21 & DIE & 2.13 & Type 3 & Path & Signing space & marked \\
\hline 22 & VERY-BAD & 3.20 & Type 3 & Path & Signing space & marked \\
\hline 23 & COOK & 3.00 & Type 3 & Path & Signing space & marked \\
\hline 24 & LIMP & 2.67 & Type 3 & Path & Signing space & unmarked \\
\hline 25 & SLEEP & 2.67 & Type 4 & Local & Eyes & Change (close) \\
\hline 26 & INTERPRETER & 2.87 & Type 4 & Local & Finger & marked \\
\hline 27 & MSN & 1.40 & Type 4 & Path & Palm & unmarked \\
\hline 28 & MALAYSIA & 1.13 & Type 4 & Path & Head & unmarked \\
\hline 29 & UNIVERSITY & 1.67 & Type 4 & Path & Head & unmarked \\
\hline 30 & PAPER & 1.53 & Type 4 & Path & Hand & unmarked \\
\hline 31 & WORTH & 2.67 & Type 4 & Path & Hand & unmarked \\
\hline 32 & QUEUE & 2.87 & Type 4 & Path & Finger & marked \\
\hline 33 & GET-OWN-BACK & $\mathrm{I} .47$ & Type 5 & Local & Hand & marked \\
\hline 34 & WORK & 1.60 & Type 5 & Path & Finger & unmarked \\
\hline 35 & RUBBISH & 1.27 & Type 5 & Path & Hand & unmarked \\
\hline 36 & NEW & 1.33 & Type 5 & Path & Palm & unmarked \\
\hline 37 & TRUE & 3.47 & Type 5 & Path & Palm & unmarked \\
\hline 38 & ENGLISH & 1.07 & Type 5 & Local & Finger & unmarked \\
\hline 39 & CHEESE & 2.00 & Type 5 & Local & Palm & unmarked \\
\hline 40 & TRANSLATE & 2.47 & Type 5 & Local & Palm & unmarked \\
\hline $4 I$ & COPY & 1.67 & Type 6 & Both & Palm & unmarked \\
\hline
\end{tabular}

(Continued) 
Appendix 2. (Continued)

\begin{tabular}{lllllll}
\hline & Gloss & Iconicity & Sign type & Movement & Location & Handshape \\
\hline 42 & DIGITAL & 2.20 & Type 6 & Both & Finger & Marked \\
43 & CALENDAR & 1.27 & Type 6 & Local & Finger & unmarked \\
44 & LESBIAN & 1.40 & Type 6 & Local & Palm & marked \\
45 & THEATRE & 1.20 & Type 6 & Local & hand & marked \\
46 & IMPORTANT & 1.73 & Type 6 & Path & Palm & unmarked \\
47 & PROMOTE & 2.33 & Type 6 & Path & Finger & marked \\
48 & PROPOSE & 2.93 & Type 6 & Path & Finger & marked \\
& Mean iconicity: & 1.98 & & & & \\
\hline
\end{tabular}

Appendix 3. List of iconic signs and their phonological properties.

\begin{tabular}{|c|c|c|c|c|c|c|}
\hline & Gloss & Iconicity & Sign type & Movement & Location & Handshape \\
\hline 1 & MOON & 4.40 & Type I & Both & Signing space & Change (close) \\
\hline 2 & AEROPLANE & 4.47 & Type I & Path & Signing space & marked \\
\hline 3 & IRON & 5.80 & Type I & Path & Signing space & unmarked \\
\hline 4 & LIGHT_BULB & 6.13 & Type I & Local & Signing space & marked \\
\hline 5 & LIGHTER & 6.20 & Type I & Local & Signing space & unmarked \\
\hline 6 & HAMMER & 6.33 & Type I & Path & Signing space & marked \\
\hline 7 & SLAP & 6.60 & Type I & Path & Signing space & unmarked \\
\hline 8 & KEY & 6.73 & Type I & Local & Signing space & marked \\
\hline 9 & INJECT & 6.93 & Type 2 & Both & Arm & Change (close) \\
\hline 10 & HEARING-AID & 6.33 & Type 2 & Path & Ear & marked \\
\hline 11 & DUCK & 6.07 & Type 2 & Local & Mouth & unmarked \\
\hline 12 & TIME & 6.87 & Type 2 & Local & Wrist & unmarked \\
\hline 13 & SMILE & 5.53 & Type 2 & Local & Mouth & Change (open) \\
\hline 14 & RHINO & 4.93 & Type 2 & Path & nose & marked \\
\hline 15 & DREAM & 4.27 & Type 2 & Path & Head & unmarked \\
\hline 16 & ICE-CREAM & 4.67 & Type 2 & Path & Mouth & marked \\
\hline 17 & ICE-SKATE & 3.60 & Type 3 & Path & Signing space & marked \\
\hline 18 & ARGUE & 4.33 & Type 3 & Path & Signing space & marked \\
\hline 19 & BICYCLE & 5.60 & Type 3 & Path & Signing space & unmarked \\
\hline 20 & CRAWL & 5.87 & Type 3 & Path & Signing space & marked \\
\hline 21 & JUGGLE & 6.80 & Type 3 & Both & Signing space & Change (open) \\
\hline 22 & GOSSIP & 6.33 & Type 3 & Both & Signing space & unmarked \\
\hline 23 & CURTAINS & 5.73 & Type 3 & Path & Signing space & marked \\
\hline 24 & INTRODUCE & 4.33 & Type 3 & Both & Signing space & unmarked \\
\hline 25 & BINOCULARS & 6.13 & Type 4 & Local & Eyes & marked \\
\hline 26 & RABBIT & 6.33 & Type 4 & Local & Head & marked \\
\hline 27 & CAMERA & 7.00 & Type 4 & Local & Eyes & marked \\
\hline 28 & BELT & 6.67 & Type 4 & Path & Waist & marked \\
\hline 29 & CRY & 6.67 & Type 4 & Path & Cheeks & unmarked \\
\hline 30 & RELAX & 4.73 & Type 4 & Local & Chest & Change (open) \\
\hline
\end{tabular}


Appendix 3. (Continued)

\begin{tabular}{lllllll}
\hline & Gloss & Iconicity & Sign type & Movement & Location & Handshape \\
\hline 31 & SHAMPOO & 5.67 & Type 4 & Path & Head & unmarked \\
32 & DEER & 5.67 & Type 4 & Path & Head & unmarked \\
33 & SAW & 5.80 & Type 5 & Path & Finger & unmarked \\
34 & CORKSCREW & 6.47 & Type 5 & Both & Hand & unmarked \\
35 & MEET & 4.87 & Type 5 & Path & Hand & unmarked \\
36 & CARDS & 5.80 & Type 5 & Local & Finger & marked \\
37 & TIE & 6.47 & Type 5 & Path & neck & marked \\
38 & VIOLIN & 6.47 & Type 5 & Path & Signing space & marked \\
39 & KNIFE & 5.67 & Type 5 & Path & Finger & marked \\
40 & DEMAND & 4.67 & Type 5 & Path & Palm & unmarked \\
41 & DRILL & 4.73 & Type 6 & Both & Palm & marked \\
42 & CLOTHES-PEG & 5.00 & Type 6 & Both & Finger & marked \\
43 & HELICOPTER & 5.40 & Type 6 & Both & Finger & unmarked \\
44 & LOCK & 6.13 & Type 6 & Local & Palm & marked \\
45 & STIR & 6.80 & Type 6 & Local & Hand & marked \\
46 & CLOCK & 5.40 & Type 6 & Local & Palm & unmarked \\
47 & WRITE & 5.80 & Type 6 & Path & Palm & marked \\
48 & BE-STRUCK-BY & 5.53 & Type 6 & Path & Finger & unmarked \\
& Mean iconicity: & 5.72 & & & & \\
\hline
\end{tabular}

